\title{
The Structural Analysis of King Parakramabahu’s Palace
}

\author{
K.K. Prabhani Auchithya Ranaweera ${ }^{1, *}$, W.K. Randesh Lilushan ${ }^{1}$, \\ D.M. Waruni Lakma Randenigama ${ }^{1}$, Kushan Kalmith Wijesundara ${ }^{2}$ \\ ${ }^{1}$ Department of Civil \& Infrastructure Engineering, Faculty of Engineering, \\ South Asian Institute of Technology and Medicine (SAITM), Sri Lanka \\ ${ }^{2}$ Department of Civil \& Infrastructure Engineering, Faculty of Engineering, University of Peradeniya, Sri Lanka
}

Copyright $@ 2017$ by authors, all rights reserved. Authors agree that this article remains permanently open access under the terms of the Creative Commons Attribution License 4.0 International License

\begin{abstract}
King Parakramabahu, (1153-1186) in Polonnaruwa monarch who built the 'Parakrama Samudra' had a magnificent seven storied palace called 'Vijayanta Prasada' or 'Vijayothpaya', the palace of God Sakra. This study has investigated the structural configuration of the palace through historical data and observation of existing part of the palace. The chronicles Chulawansa and Mahawansa has described the palace as seven storied building with thousand chambers. Though the main building possibly cannot hold such a number of chambers, considering the whole palace complex this number seems a possible. The research was being conducted using the existing brick wall and was used to identify the column beam configuration and how the load path was distributed. During the research the load path from the upper floors to the ground was also investigated. The dimensions of all the existing structural components were taken into consideration. The results revealed that the upper floors could have been made out of timber such as Weera and Palu and the existing wall must have held the massive wooden structure that form the floor of the upper level. The study was conducted in order to prove that the ancestors who lived 1000 years ago also used a method similar to Euler - Bernouli beam theorem for constructions.
\end{abstract}

Keywords Euler - Bernouli Beam Theorem, Structural Configuration, Load Path

\section{Introduction}

Parakramabahu Palace, called Vijayanta Prasada, is a magnificent seven-story structure which was built by King Parakramabahu (1153-1186), the great Polonnaruwa ruler who built the Parakrama Samudra. Although much of it is now in utter devastation, one can imagine how grand it once used to be. According to chronicles it is believed that this palace had seven stories with 1000 chambers [1]. Even today once you entered into the palace complex you can see the ruins of three stories of bricks. If correct this palace would have as tall as one of the first doctors and wealthy vendors [2].

As depict in Figure 1.2 the remaining walls show grooves where timber columns with beams and wooden floors rose up like a step pyramid, reducing in area as with each floor. According to the Mahawansa [1], one of main ancient chronicles of Sri Lanka which represents the Sri Lankan history stated that the king Parakramabahu's Palace was in square shape and the diagonal of the palace intersect in the middle of the palace and the diagonal from the outer wall intersect in front of the front door of the palace. It is believed that the area outside the palace was reserved for the executive members of the palace such as ministers, skyscrapers, the seven stories Equitable Life Building in US, built in 1870 .

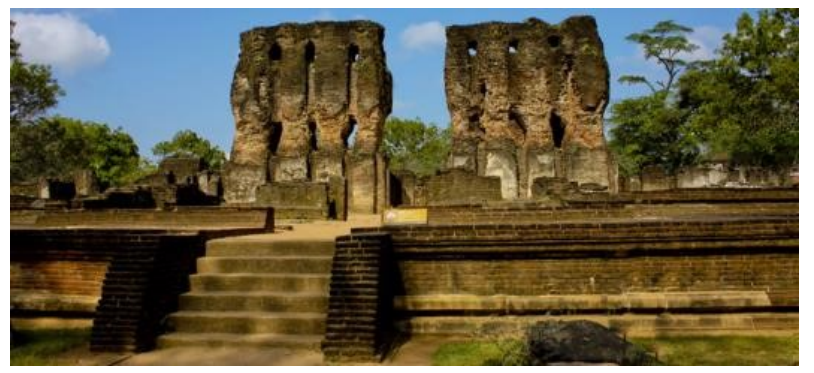

Figure 1.1. Recently taken photo of King Parakramabahu’s Palace

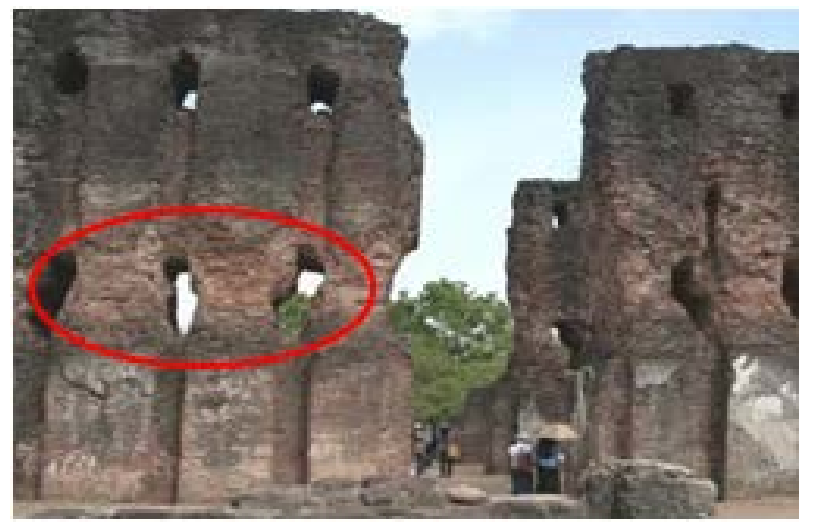

Figure 1.2. It is assumed that large beams had been fitted to these huge grooves 
The palace consists of one main wall surrounded by 40 interconnecting rooms. The palace and its courtyard are protected by walls, which were then encircled with another outer wall. Today, the massive walls over a meter thick going up to about 30 feet (9 meters) and also the bottom half of the main stairway which led to upper floors can only be seen as shown in Figure 1.3. After doing excavations, now the archaeologists also doubt whether our ancestors have used something similar to a lift to go to upper floors. This was considered because this place was the living arena of the king and it is highly unlikely that the king climbed steps to go to the upper floors.

Large holes in the wall probably held massive wooden beams that formed the floor of the upper levels. The loads of the upper floor were directed to the ground via these beams so that may be the reason of using large dimensions for the beams. Even after facing such destruction by human hand and then by Mother Nature for 800 years, the plastering on these walls still remain in some places. As shown n Figure 1.4 the plastering of the wall is still intact in some areas and it was believed that the palace was destroyed due to a fire caused by Tamil invaders. The records of the archaeologists suggest that this would have been one of the tallest occupied buildings in the world at the time and the foundation is still impressive almost 1,000 years later.

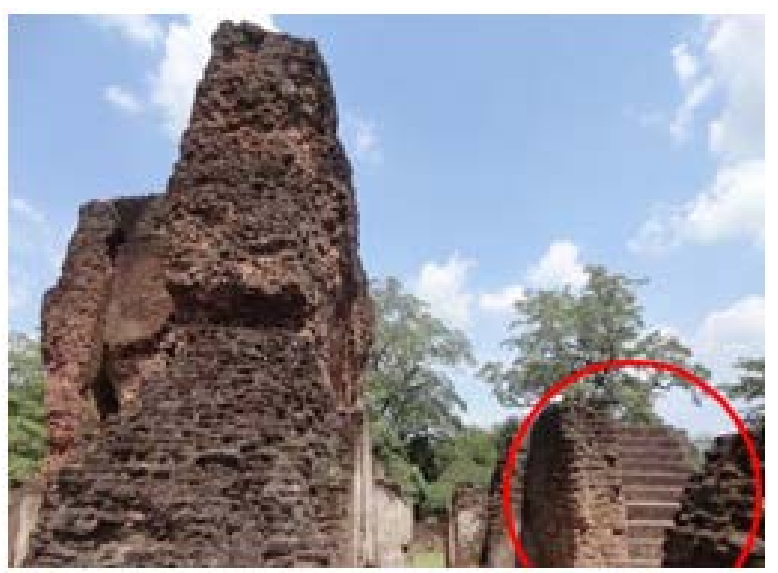

Figure 1.3. Existing parts of the palace. Circled section shows the remaining staircase for upper floors.

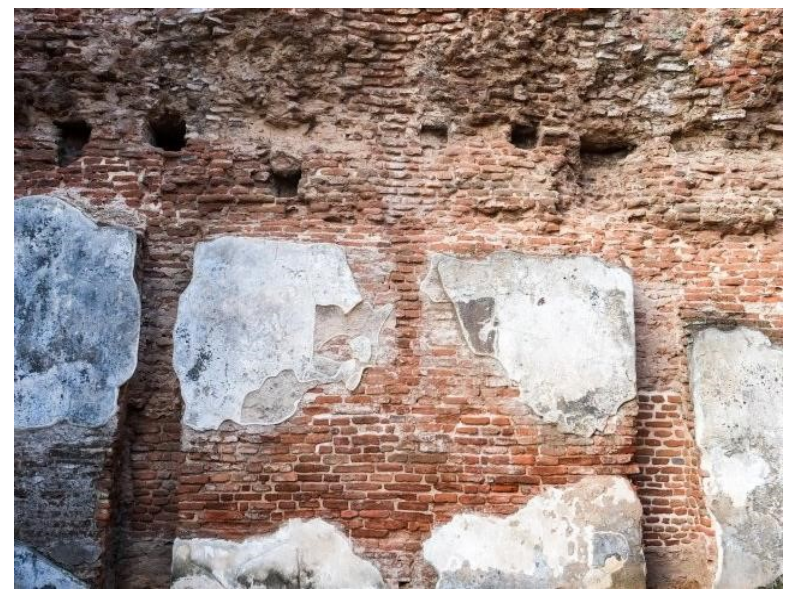

Figure 1.4. Existing plastering on the walls of the palace
The wooden columns and beams which are used in upper floors are assumed to be made of Manilkarahexandra (Palu) and Vera which have a considerable strength (about $40 \mathrm{MPa}$ ). An architect's impression of what it would have looked can be seen at the Polonnaruwa museum in a form of miniature model.

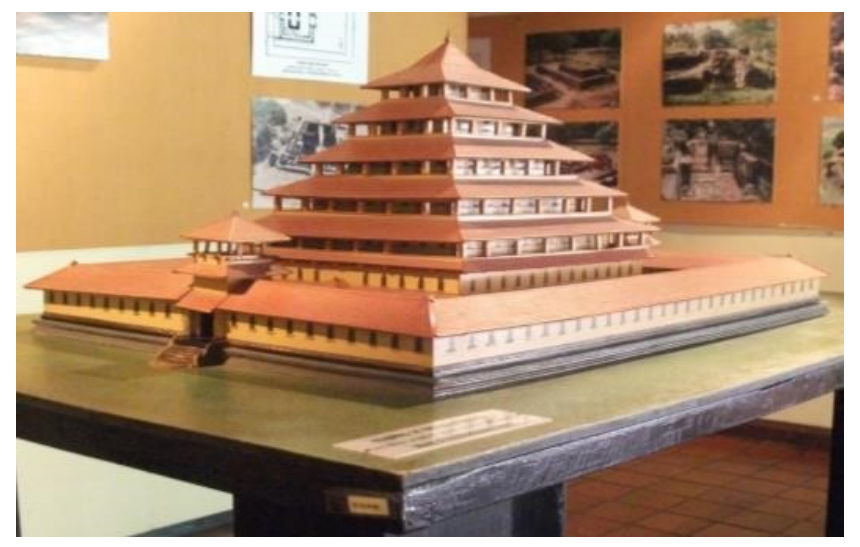

Figure 1.5. Miniature model of King Parakramabahu's Palace according to architecture's impression

The solid mechanics theory of beams commonly known as beam theory and it has a main role in structural analysis as it provides simple tools to analyze numerous structures [3]. This study was mainly conducted by using Euler - Bernouli beam theorem in order to prove its application during our ancestor's period. Euler - Bernouli beam theory [4] which is also known as Engineer's beam theorem is the explanation of the linear theory of elasticity. It provides the means of calculating the load carrying and deflection characteristics of the beam.

There are three assumptions that must be taken into consideration when using the Euler - Bernouli beam theorem. Furthermore experiments had proved that following assumptions are valid for long and slender beams. According to Bauchau and Craig [3] the cross-section must infinitely rigid in its own plane. Secondly the cross-section of the beam remains plane after deformation and finally the cross-section must remain normal to the deformed axis of the beam.

\section{Methodology}

\section{Structural Configurations}

Based on the historical information in the MahaWansa [1] and ChulaWansa [2] and the field surveying on the existing part the palace, structural configuration of the palace is discussed in this study.

\subsection{Column Layout}

The remaining walls show some grooves like continuous vertical spaces which can be assumed as there were timber columns among those spaces to hold this massive structure. 
One column was about 10 meters in height. There were exactly 64 such grooves like spaces on the ground floor which can be taken as column. Distances between columns along the column line were measured as roughly 1.4 meters. The following Figure 2.1 shows the column layout of the palace. The image was drawn by hand after a site visit and after taking the dimensions of each and every column hole. The shaded area depicts the palace limits where the royal family lived. As it is shown the palace is symmetrical and the numbers of columns in both sides are equal. Lots of studies are undergoing in that area in order to find the dimensions of columns as well as other hidden miracles of this palace which prove the knowledge that our ancestors possessed.

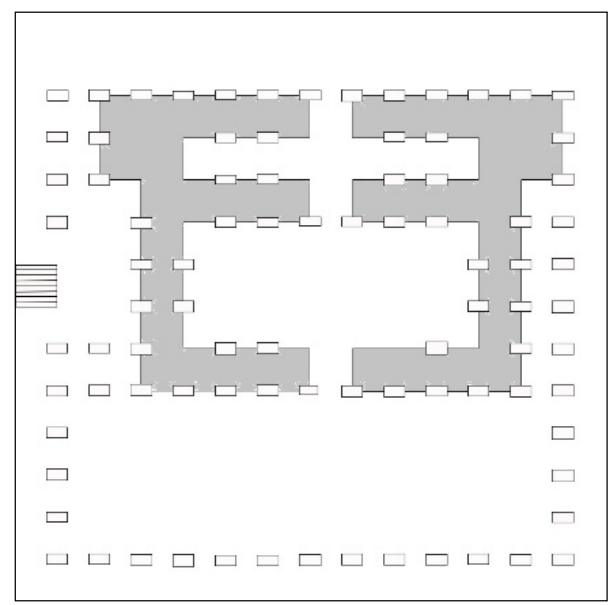

Figure 2.1. Column layout of the ground floor

\subsection{Beam Layout}

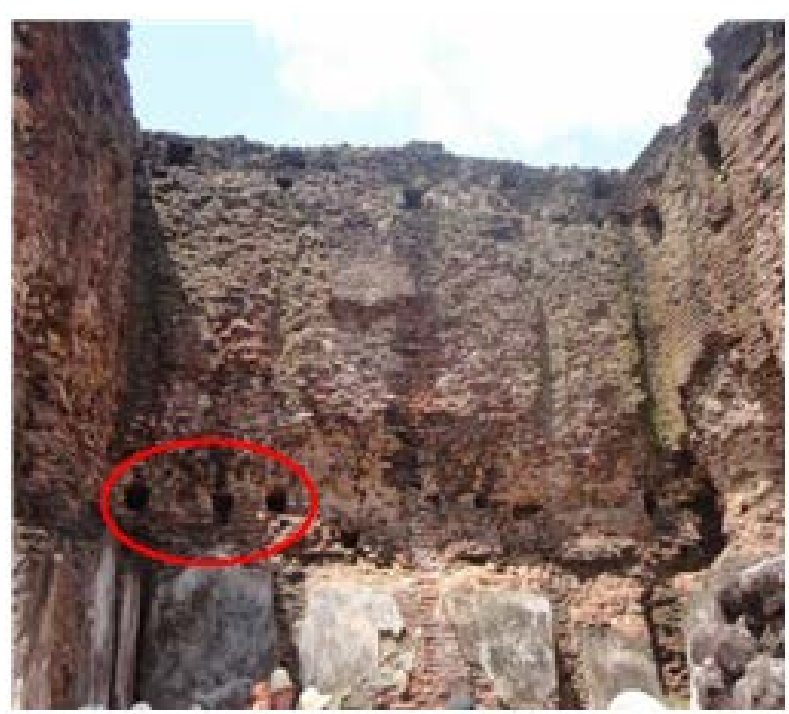

Figure 2.2. Grooves which hold cross beams

The voids in the remaining walls suggested the size of the cross sections of main and cross beams which were the timber floor slab and there were about seven such larger voids for main beams and seven smaller voids for transverse beams in the perimeter of the wall. It is believed that the beams also made of timber. The beams and the cross beams are used in order direct load of the upper floors to the ground. Based on that observation, floor beam layouts were planned.

\section{Calculation}

Sample calculation for third floor:

\subsection{Beam Layout}

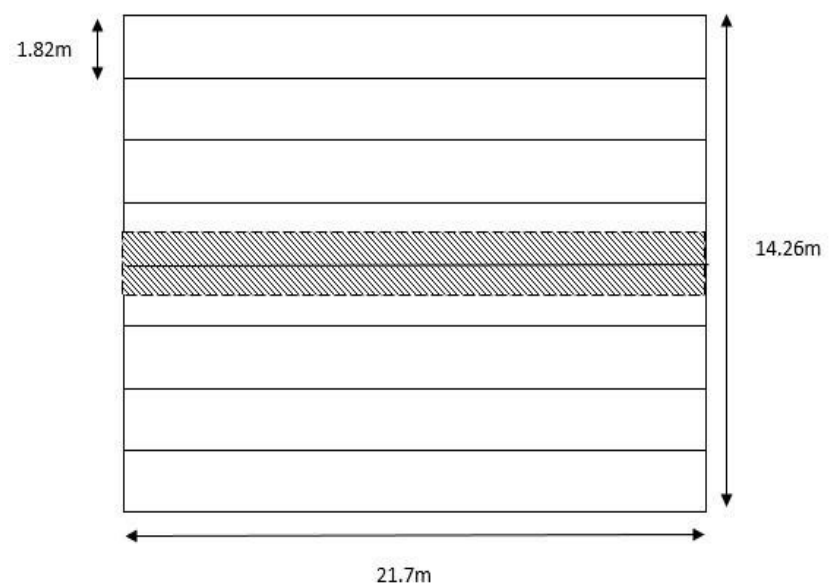

Figure 3.1. Third floor beam layout

Figure 3.1 depicts the beam layout of the third floor. The dimensions were assumed by taking the measurements of the palace.

\subsection{Beam}

The following Figure 3.2 represents the schematic diagram of a beam in third floor. It also depicts the point loads and uniform load from the upper floors.

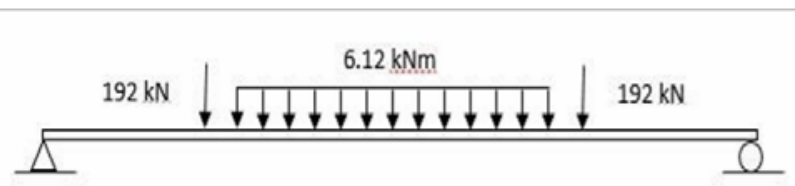

Figure 3.2. Schematic diagram of the beam

\subsection{Bending Moment Diagram}

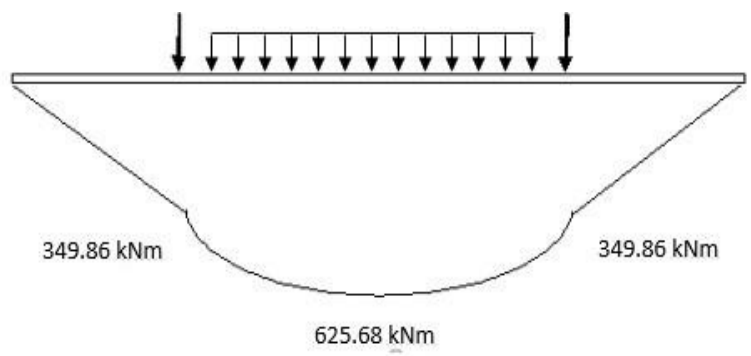

Figure 3.3. the bending moment diagram of the beam 
The above diagram, Figure 3.3 shows the bending moment diagram of the beam. The maximum moment is around $626 \mathrm{kNm}$ and it acts at the middle of the beam.

\section{Flexure Formula}

$$
\begin{aligned}
& \text { Flexure formula } \\
& \qquad \begin{aligned}
\frac{\mathrm{M}}{\mathrm{I}} & =\frac{\sigma}{\mathrm{y}}=\mathrm{E} \phi \\
\sigma & =\frac{\mathrm{MY}}{\mathrm{I}} \\
\sigma_{\text {allowable }} & =\frac{40 \times 10^{3}}{1.5} \\
\mathrm{I} & =\frac{1}{12} \mathrm{~b}^{4} \\
\mathrm{~b} & =520.21 \mathrm{~mm}
\end{aligned}
\end{aligned}
$$

$\mathrm{M}=$ Moment at a given cross-section of a beam

$\mathrm{I}=$ Moment of inertia of cross-section

$\mathrm{O}=$ Bending stress at $\mathrm{y}$ distance

$\mathrm{y}=$ Distance from the neutral axis

$\mathrm{E}=$ Young's modulus

Flexure formula is being used to find the beam size. The allowable stress of wood was found as $40 \mathrm{MPa}$ and it was divided by a Factor of Safety of 1.5. The cross section of the beam was assumed as a square so that both width and the depth were taken as b. By using the theorem the depth was found as $520.21 \mathrm{~m}$.

Table 3.1. Beam size and maximum bending moment of each floor

\begin{tabular}{|c|c|c|}
\hline Floor & $\begin{array}{c}\text { Maximum } \\
\text { B.M.(kNm) }\end{array}$ & Beam size(mm) \\
\hline $1^{\text {st }}$ floor & 625.68 & 520.21 \\
\hline $2^{\text {nd }}$ floor & 625.68 & 520.21 \\
\hline $3^{\text {rd }}$ floor & 625.68 & 520.21 \\
\hline $4^{\text {th }}$ floor & 461.47 & 470.01 \\
\hline $5^{\text {th }}$ floor & 322.78 & 417.22 \\
\hline $6^{\text {th }}$ floor & 204.38 & 358.27 \\
\hline
\end{tabular}

The above Table 3.1 depicts the maximum bending moment and the beam sizes in first to sixth floors. As it show the maximum bending moment was given in $1^{\text {st }}, 2^{\text {nd }}$ and $3^{\text {rd }}$ floors while the $6^{\text {th }}$ floor gives the minimum bending moment. Beam size also varies from floor to floor and the biggest dimensions were given in $1^{\text {st }}, 2^{\text {nd }}$ and $3^{\text {rd }}$ floors while the $6^{\text {th }}$ floor gives the minimum beam size.

\section{Results}

\subsection{Load Path}

Seventh floor is supported by 4 columns beneath it and the total load of the roof and the columns are resisted by the floor below it (sixth floor), likewise the total load below that floor is transferred to the columns below equally.

The load of the second floor is transferred to the first floor and then from the first floor through the columns to the ground.

The estimated width of a beam (size of existing voids) was approximately about 10 bricks $(60 \mathrm{~cm})$ although the calculated one differed from about $7 \mathrm{~cm}(53 \mathrm{~cm})$.

Table 4.1. Theoretical dimension vs. experimental dimensions of floors

\begin{tabular}{|c|c|c|}
\hline Floor & $\begin{array}{c}\text { Theoretical } \\
\text { dimensions(mm) }\end{array}$ & $\begin{array}{c}\text { Experimental } \\
\text { dimensions(mm) }\end{array}$ \\
\hline $1^{\text {st }}$ floor & 520.21 & 600.00 \\
\hline $2^{\text {nd }}$ floor & 520.21 & 600.00 \\
\hline $3^{\text {rd }}$ floor & 520.21 & 600.00 \\
\hline
\end{tabular}

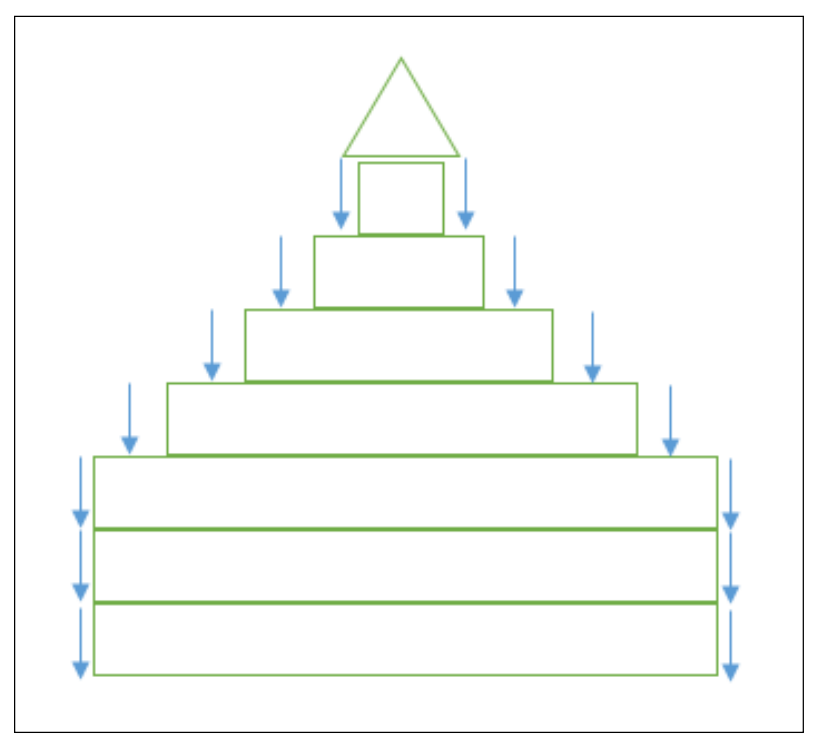

Figure 4.1. Load is transferred from seventh floor to the first floor through columns (Load path)

\section{Conclusions}

King Parakramabahu the great ruled Sri Lanka from 1153 to 1186 . During his reign he had done excellent constructions and his palace is one of them. It is proved that the dimensions that were taken during our site visit to the Palace were nearly equal to the dimensions that we got through theoretical methods. In this study we used the simple beam theory or the Euler - Bernouli beam theorem to find the depth of the beams. This proves that our ancestors had a very good knowledge on theories of Structural Engineering even at those times. Sri Lanka is a country with a lot of historical buildings. Our ancestors had built enormous chetiyas such as Ruwanvelisaya, Jethavanaramaya and Abayagiriya even before these theories were proved. It is confirmed that they had used a theory similar to Euler-Bernoulli theorem or else a theory which was far more advanced than the beam theory for their constructions. 


\section{Future Recommendations}

Since this study was conducted with basic resources there can be doubts about the accuracy so the measurements and deeper studies can be conducted with better resources. Furthermore this can be used as a guideline and do further studies about the chetiyas that were built during this era in order to get a better idea about the theories and the methods that they were use

\section{REFERENCES}

[1] Mahawansa - Kurunegala Era

[2] Chulawansa

[3] Bauchau O.A. and Craig J. I, 2009. "Euler- Bernouli beam theorem” in Structural Analysis, Volume 163, pp 173-221.

[4] Timoshenko, S. 1953. "History of strength of materials", New York: McGraw-Hill. 